\section{Community-Associated MRSA Infection in Remote Amazon Basin Area, Peru}

\section{Coralith García, Lizeth Astocondor, Jinnethe Reyes, Lina P. Carvajal, Cesar A. Arias, Carlos Seas}

Author affiliations: Universidad Peruana Cayetano Heredia, Lima, Peru (C. García, L. Astocondor, C. Seas); Hospital Nacional Cayetano Heredia, Lima (C. García, C. Seas); Universidad EI Bosque, Bogotá, Colombia (J. Reyes, L.P. Carvajal, C.A. Arias); University of Texas Medical School at Houston, Houston, Texas, USA (C.A. Arias)

DOI: http://dx.doi.org/10.3201/eid2205.151881

To the Editor: Two predominant community-associated methicillin-resistant Staphylococcus aureus (CAMRSA) clones have been reported in South America: 1) sequence type 30 staphylococcal cassette chromosome mec IV (ST30-SCCmec IV) (USA 1100), first found in Uruguay (2002) and later in Brazil and Argentina (2005); and 2) ST8$\mathrm{SCC} m e c$ IVc/E (USA300-Latin American variant), found predominantly in Ecuador and Colombia (2006-2008) (1). In hospitals in Colombia, USA300-Latin American variant has replaced the most common hospital-associated lineage, known as the Cordobes/Chilean clone (MRSA ST5-SCCmec I) (2). In Peru, a limited number of imported cases of CA-MRSA have been reported (3). We describe a case of CA-MRSA infection in a patient living in a remote area of the Amazon Basin of Peru.

The patient was a 58-year-old woman who was hospitalized in June 2014 for a skin ulcer. She had been well until 10 days before admission, when she noticed a papule on her right arm, followed the next day by localized swelling and redness. Three days later, spontaneous secretion of a purulent material was noted. At the time of admission, the patient had no fever or constitutional symptoms; the ulcer was deep with irregular borders $(\approx 10 \times 4 \mathrm{~cm})$ and active purulent secretion (Figure, panel A). Other physical examination findings were unremarkable.

For the past 2 years, the patient had lived in a remote, rural, jungle village in Peru. She was a housewife but also farmed in nearby areas. There were ducks, chickens, and guinea pigs on the farm where she lived. Her village had neither running water nor roads and almost no access to healthcare (reaching the nearest healthcare center required a 36-hour boat trip). She previously experienced several episodes of malaria (most recently in February 2014), for which she received antimalarial medication provided by a Brazilian military post at the border of Peru. She had

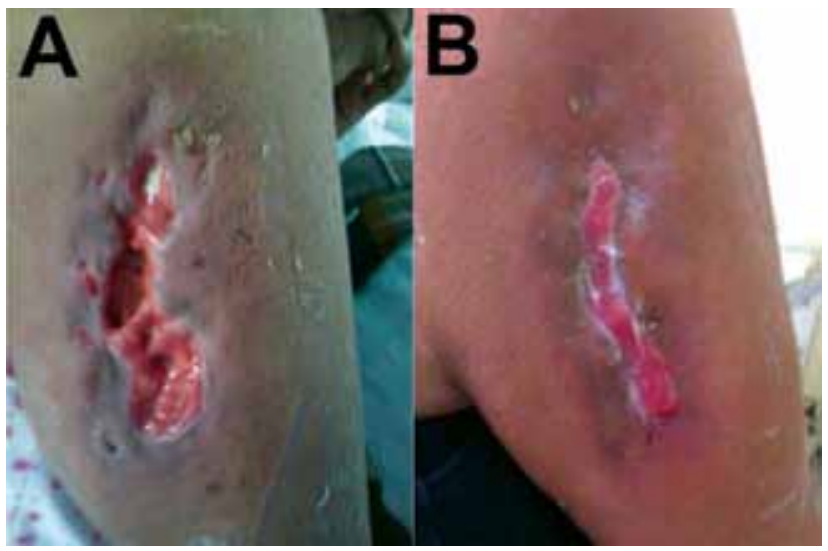

Figure. A) Untreated community-associated methicillin-resistant Staphylococcus aureus ulcer on the right arm of a 58-year old woman from a rural area of the Amazon Basin, Peru. B) The same ulcer after 19 days of treatment with vancomycin and trimethoprim/ sulfamethoxazole.

never taken antimicrobial drugs and had not traveled in the past 2 years. She first noticed the skin lesion on the first day of an 8-day boat trip from her home village to Iquitos, the largest city in the Peruvian Amazon Basin.

Cultures from wound exudate and skin biopsy samples yielded $S$. aureus resistant to oxacillin, tetracycline, and erythromycin and susceptible to ciprofloxacin, gentamicin, rifampin, and trimethoprim/sulfamethoxazole (susceptibility testing performed by an agar dilution method). D test showed inducible resistance to clindamycin. The presence of $m e c A$ and the genes (lukS-PV, lukF-PV) encoding Panton-Valentine leucocidin (PVL) were confirmed by PCR.

The isolate was characterized as MRSA ST6-t701$\mathrm{SCCmec} \mathrm{V}$. Whole-genome sequence analyses identified a predicted protein with $100 \%$ aa identity ( $98 \%$ coverage) to the truncated b-hemolysin of the reference genome of S. aureus USA300_FPR3757 (GenBank accession no. $\mathrm{gb}|\mathrm{ABD} 20946.1|)$ and the prophage groups 1, 2, and 3. Pulsed-field gel electrophoresis (PFGE) exhibited a pulsotype different from other typical CA-MRSA PFGE patterns found in MRSA from Latin America, labeled as CAMRSA 120 (online Technical Appendix, http://wwwnc. cdc.gov/EID/article/22/5/15-1881-Techapp1.pdf). Intravenous clindamycin (600 mg every 8 hours for 5 days) was empirically prescribed, after which treatment was switched to vancomycin (1 g every 12 hours for 1 week). Subsequently, the patient received trimethoprim/sulfamethoxazole (160/800 mg every 12 hours for 1 week). The clinical evolution was satisfactory, and the infection resolved (Figure, panel B).

This case of a skin and soft tissue infection caused by a CA-MRSA ST6-t701-SCCmec V PVL-producing organism is notable for several reasons. First, infection occurred in a remote rural jungle area of Peru at the border with Brazil 
and Colombia and resembles the first cases of CA-MRSA described in the early 1990s as occurring in indigenous people living in remote areas of Western Australia (4). Second, considering that the most predominant CA-MRSA clones in Latin America carry SCCmec IV (1,5), finding SCCmec V in this isolate was not expected. MRSA carrying SCCmec $\mathrm{V}$ have been well characterized as colonizers and agents of infection in animals and in humans in close contact with animals (mainly in Europe but also in other parts of the world) (6). These livestock-associated MRSA clones predominantly belong to ST97 (which are usually not PVL producers) and ST398. In addition, ST398 SCCmec V MRSA isolates from pigs in Peru have been described (7). Of note, methicillin-susceptible $S$. aureus t701 and MRSA t701 carrying $\mathrm{SCCmec}$ II have recently been found in China, isolated from patients during food poisoning outbreaks and from colonized pork butchers, respectively $(8,9)$. In South America, isolation of non-PVL-producing MRSA t701 (carrying $\mathrm{SCCmec}$ IVc) and methicillin-sensitive S. aureus $\mathrm{t} 701$ from colonized inpatients has been well described (10). Although speculation that animal carriage might have played a role in this infection is tempting, further studies are needed to recognize the origin of this MRSA ST6-SCCmec V PVL producer in this area of the Amazon Basin.

\section{References}

1. Reyes J, Rincón S, Díaz L, Panesso D, Contreras GA, Zurita J, et al. Dissemination of methicillin-resistant Staphylococcus aureus USA300 sequence type 8 lineage in Latin America. Clin Infect Dis. 2009;49:1861-7. http://dx.doi.org/10.1086/648426

2. Reyes J, Arias C, Carvajal L, Rojas N, Ibarra G, Garcia C, et al. MRSA USA300 variant has replaced the Chilean clone in Latin American hospitals. 2012. Abstract presented at: the Interscience Conference on Antimicrobial Agents and Chemotherapy; 2012 Sep 9-12; San Francisco, CA, USA.

3. García C, Deplano A, Denis O, León M, Siu H, Chincha O, et al. Spread of community-associated methicillin-resistant Staphylococcus aureus to Peru. J Infect. 2011;63:482-3. http://dx.doi.org/10.1016/j.jinf.2011.09.001

4. Udo EE, Pearman J, Grub W. Genetic analysis of community isolates of methicillin-resistant Staphylococcus aureus in Western Australia. J Hosp Infect. 1993;25:97-108. http://dx.doi.org/ 10.1016/0195-6701(93)90100-E

5. Ma XX, Galiana A, Pedreira W, Mowszowicz M, Christophersen I, Machiavello S, et al. Community- acquired methicillin-resistant Staphylococcus aureus, Uruguay. Emerg Infect Dis. 2005;11: 973-6. http://dx.doi.org/10.3201/eid1106.041059

6. Spoor LE, Mcadam PR, Weinert LA, Rambaut A, Hasman H, Aarestrup FM, et al. Livestock origin for a human pandemic clone of community-associated methicillin-resistant Staphylococcus aureus. MBio. 2013;4:1-6.

7. Arriola CS, Guere M, Larsen J, Skov RL, Gilman RH, Armando E, et al. Presence of methicillin-resistant Staphylococcus aureus in pigs in Peru. PLoS ONE. 2011;6: e28529. http://dx.doi.org/10.1371/journal.pone.0028529

8. Li G, Wu S, Luo W, Su Y, Luan Y, Wang X. Staphylococcus aureus ST6-t701 isolates from food-poisoning outbreaks (2006-2013)

in Xi'an, China. Foodborne Pathog Dis. 2015;12:203-6. http://dx.doi.org/10.1089/fpd.2014.1850
9. Boost M, Ho J, Guardabassi L, O’Donoghue M. Colonization of butchers with livestock-associated methicillin-resistant Staphylococcus aureus. Zoonoses Public Health. 2013;60:572-6. http://dx.doi.org/10.1111/zph.12034

10. Bartoloni A, Riccobono E, Magnelli D, Villagran AL, Di Maggio T, Mantella A, et al. Methicillin-resistant Staphylococcus aureus in hospitalized patients from the Bolivian Chaco. Int J Infect Dis. 2015;30:156-60. http://dx.doi.org/10.1016/j.ijid.2014.12.006

Address for correspondence: Coralith Garcia, Instituto de Medicina Tropical Alexander von Humboldt, Universidad Peruana Cayetano Heredia, Av. Honorio Delgado 430, Lima 31, Peru; email: coralith.garcia@upch.pe

\section{Exposure to Bat-Associated Bartonella spp. among Humans and Other Animals, Ghana}

\author{
Alexandra O. Mannerings, ${ }^{1}$ Lynn M. Osikowicz, \\ Olivier Restif, Edward Nyarko, \\ Richard Suu-Ire, Andrew A. Cunningham, \\ James L.N. Wood, Michael Y. Kosoy
}

Author affiliations: University of Cambridge, Cambridge, UK (A.O. Mannerings, O. Restif, J.L.N. Wood); Zoological Society of London, London, UK (A.O. Mannerings, A.A. Cunningham); Centers for Disease Control and Prevention, Fort Collins, Colorado, USA (L.M. Osikowicz, M.Y. Kosoy); Public Health Division, 37 Military Hospital, Accra, Ghana (E. Nyarko); Forestry Commission, Accra (R. Suu-Ire).

DOI: http://dx.doi.org/10.3201/eid2205.151908

To the Editor: Human contact with wildlife is a leading cause of disease spillover. Bats, in particular, host numerous zoonotic pathogens, from henipaviruses to lyssaviruses (1). In Ghana, the straw-colored fruit bat (Eidolon helvum) frequently and closely interacts with humans through roosting in urban areas and human harvesting of bushmeat. Large colonies live in Accra, the capital city, and $>128,000$ bats, on average, are hunted for food yearly in southern Ghana alone (2). Serologic evidence of human infection with novel paramyxoviruses from $E$. helvum bats (3) supports concerns regarding this contact. In addition, Kosoy et al. (4) isolated several new strains of Bartonella that were found in $>30 \%$ of $E$. helvum bats, whereas Billeter et al. found Bartonella in $66 \%$ of their ectoparasites (5), with Bartonella transmissibility to other species unknown. This prevalence causes concern because many Bartonella

${ }^{1}$ Current affiliation: Colorado Hospital Association, Greenwood Village, Colorado, USA. 